UDC: $519.622,004.021,004.942$

\title{
2D microscopic and macroscopic simulation of water and porous material interaction
}

\author{
E. G. Nikonov ${ }^{1, a}$, M. Pavluš ${ }^{2, b}$, M. Popovičová ${ }^{2, c}$ \\ ${ }^{1}$ Joint Institute for Nuclear Research, \\ Jolio-Curie st. 6, Dubna, Moscow region, 141980, Russia \\ ${ }^{2}$ University of Prešov, \\ Konštantinova st. 16, Prešov, 080 01, Slovakia \\ E-mail: ${ }^{\mathrm{a}}$ e.nikonov@jinr.ru, ${ }^{\mathrm{b}}$ miron.pavlus@unipo.sk, ${ }^{\mathrm{c}}$ maria.popovicova@unipo.sk
}

Received 15.09.2017, after completion - 24.01.2018. Accepted for publication 24.01.2018.

In various areas of science, technology, environment protection, construction, it is very important to study processes of porous materials interaction with different substances in different aggregation states. From the point of view of ecology and environmental protection it is particularly actual to investigate processes of porous materials interaction with water in liquid and gaseous phases. Since one mole of water contains $6.022140857 \cdot 10^{23}$ molecules of $\mathrm{H}_{2} \mathrm{O}$, macroscopic approaches considering the water vapor as continuum media in the framework of classical aerodynamics are mainly used to describe properties, for example properties of water vapor in the pore. In this paper we construct and use for simulation the macroscopic two-dimensional diffusion model [Bitsadze, Kalinichenko, 1980] describing the behavior of water vapor inside the isolated pore. Together with the macroscopic model it is proposed microscopic model of the behavior of water vapor inside the isolated pores. This microscopic model is built within the molecular dynamics approach [Gould et al., 2005]. In the microscopic model a description of each water molecule motion is based on Newton classical mechanics considering interactions with other molecules and pore walls. Time evolution of "water vapor-pore" system is explored. Depending on the external to the pore conditions the system evolves to various states of equilibrium, characterized by different values of the macroscopic characteristics such as temperature, density, pressure. Comparisons of results of molecular dynamic simulations with the results of calculations based on the macroscopic diffusion model and experimental data allow to conclude that the combination of macroscopic and microscopic approach could produce more adequate and more accurate description of processes of water vapor interaction with porous materials.

Keywords: porous media, molecular dynamics, macroscopic diffusion model

Citation: Computer Research and Modeling, 2018, vol. 10, no. 1, pp. 77-86 (Russian).

This work is supported by JINR project No. 05-6-1118-2014/2019, protocol No. 4596-6-17/19. 


\title{
Двумерное макроскопическое и микроскопическое моделирование процессов взаимодействия воды и пористых материалов
}

\author{
Э. Г. Никонов ${ }^{1, \mathrm{a}}$, М. Павлуш ${ }^{2, \mathrm{~b}}$, М. Поповичова ${ }^{2, \mathrm{c}}$ \\ ${ }^{1}$ Объединенный институт ядерных исследований, \\ 141980, г. Дубна, Московская область, ул. Жолио-Кюри, д. 6 \\ ${ }^{2}$ Университет г. Прешов, \\ Словакия, 080 01, г. Прешов, ул. Конштантинова, д. 16 \\ E-mail: ${ }^{\mathrm{a}}$ e.nikonov@jinr.ru, ${ }^{\mathrm{b}}$ miron.pavlus@unipo.sk, ${ }^{\mathrm{c}}$ maria.popovicova@unipo.sk \\ Получено 15.09.2017, после доработки - 24.01.2018. \\ Принято к публикации 24.01.2018.
}

В различных областях науки, техники, защиты окружающей среды, в строительстве актуальными являются вопросы изучения процессов взаимодействия пористых материалов с веществами, находящимися в различных агрегатных состояниях. Особенно актуальными с точки зрения экологии и защиты окружающей среды являются исследования процессов взаимодействия пористых материалов с водой в жидкой и газообразной фазе. Поскольку в одном моле воды содержится 6.022140857 $10^{23}$ молекул $\mathrm{H}_{2} \mathrm{O}$, для описания свойств, например, водяного пара в поре в основном используются макроскопические подходы, рассматривающие водяной пар как сплошную среду в рамках аэродинамики. В данной работе построена и использовалась для моделирования макроскопическая двумерная диффузионная модель [Bitsadze, Kalinichenko, 1980] поведения водяного пара внутри изолированной поры. Наряду с макроскопической моделью в работе предложена микроскопическая модель поведения водяного пара внутри изолированной поры, построенная в рамках молекулярно-динамического подхода [Gould et al., 2005]. В данной модели на основе классической механики Ньютона описывается движение каждой молекулы воды, взаимодействующей как с другими молекулами воды, так и со стенками поры. Рассматривается эволюция системы «водяной пар-пора» с течением времени. В зависимости от внешних по отношению к поре условий система эволюционирует к различным состояниям равновесия, которые характеризуются различными значениями макроскопических характеристик, таких как температура, плотность, давление. Сравнение результатов молекулярно-динамического моделирования с результатами вычислений на основе макроскопической диффузионной модели и экспериментальными данными позволяет сделать вывод о необходимости сочетания макроскопического и микроскопического подхода для адекватного и более точного описания процессов взаимодействия водяного пара с пористыми материалами.

Ключевые слова: пористые среды, молекулярная динамика, макроскопическая диффузионная модель

Работа выполнена в рамках проекта ОИЯИ № 05-6-1118-2014/2019, протокол № 4596-6-17/19. 


\section{Introduction}

Experimental and theoretical investigations of liquid and gas interaction with porous media are very important for many fields of science and technology. An interaction of water in various phase states with construction materials; filtering and separation of different substances in chemical, biological industries and medicine; protection against toxic and radioactive substances in gaseous and droplet forms etc. This is not a complete list of fields where it is very necessary to have an information about characteristics of processes of water interaction with porous media. Porous materials can be organic or inorganic origin. The most frequent porous materials are organic materials, polymeric foams etc. A large number of inorganic porous materials has also been developed, e.g. for insulation, cushioning, impact protection, catalysis, membranes, construction materials etc.

Porous material can be of the following types:

- materials with different pore sizes (from nanometer to millimeter);

- ordered or irregular arrangement of pores;

- various chemical compositions (metal, oxides, ...);

- preparated by different way on the base of various preparative approaches.

Pores can be distinguishes by the following features: accessibility and shape. Accessibility means that pores can be of the following types: closed pores, open pores, blind pores (also called dead-end or saccate pores) and through pores. Shape means that pores can be of the following types: cylindrical open, cylindrical blind, ink-bottle-shaped, funnel shaped and roughness [Rouquerol et al., 1994].

Moreover, in accordance with the IUPAC ${ }^{1}$ classification, pores are characterized by their sizes [McNaught, Wilkinson, 1997].

- Micropores (smaller than $2 \mathrm{~nm}$ ): larger than typical mean free path length of typical fluid.

- Mesopores (between 2 and $50 \mathrm{~nm}$ ): same order or smaller than the mean free path length.

- Macropores (larger than $50 \mathrm{~nm}$ ): pore size comparable to the molecules.

All artificial and natural porous material have a very complicated porous structure with pores of very intricate geometrical forms. So if we need to accurately describe processes of water-pore interaction for individual pore we need to numerically solve, for example, diffusion equation with very complicated boundary conditions. In this case, if we use molecular dynamic for finding of, for example, diffusion coefficient space distribution, we can get more accurate numerical solution for diffusion equations. Evidently this approach is justified if and only if it is necessary to obtain a description of water interaction with individual pore as accurate as possible.

In this paper we compare continual macroscopic diffusion model and discrete microscopic molecular dynamic model to investigate differences between these two approaches in description of water vapor interaction with individual pore. The main purpose of this work is to test our "hybrid" approach for 2D very simple model of "water vapor-pore" interaction using very restricted model water molecules moving only along two directions. We will use this approach further for 3D simulation and then it will be possible to make some interpretation obtained simulation results.

\section{General problem}

Because of a high level of complexity of water-pore interaction which heavily depends on the form of the pore we consider in our work as the first step of investigation two-dimensional (2D) model of a slit-like pore with cross-section as shown in figure 1.

\footnotetext{
${ }^{1}$ The International Union of Pure and Applied Chemistry.
} 


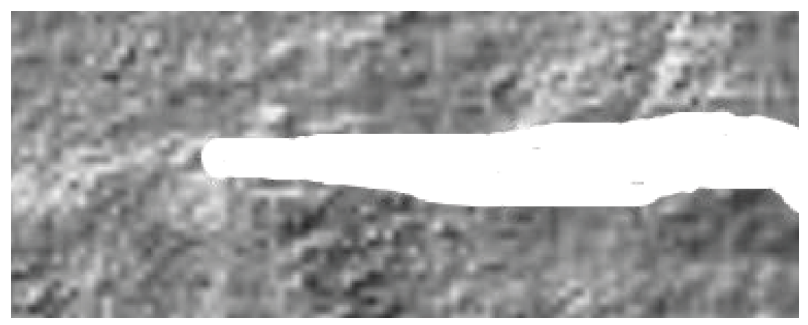

Fig. 1. Cross-section of slit-like pore

At this stage of our research, we use a fairly simple model of slit-like pore. We study all processes in the volume of a rectangular prism with an area equal to the cross section of the pore and a height equal to the diameter of the water molecule. Further in the paper we compare micro and macro approaches for describing of water vapor interaction with 2D slit-like pore. Micro approach is based on "ab initio" molecular dynamic simulations. And macro approach is based on macroscopic diffusion model. The main goal of our investigation is understanding of possibilities to combine the two approaches to achieve higher accuracy in description of processes in real "water-pore" systems.

\section{Molecular dynamic model}

Molecular dynamic simulation of microscopic system evolution is based on representation of object modeling as a system of interacting particles (atoms or molecules). The evolution of the system is a result of a motion of the particles mentioned above. Particle coordinates in each subsequent time step are calculated by integration of equations of motion. These equations contain potentials of particle interactions with each other and with an external environment.

In classical molecular dynamics, the behaviour of an individual particle is described by the Newton equations of motion [Gould et al., 2005; Shaytan, Saraykin, 1999].

In our work for a simulation of particle interaction, we use Lennard-Jones potential [LennardJones, 1924] with parameters $\sigma=3.17 \AA$ and $\varepsilon=6.74 \cdot 10^{-3} \mathrm{eV}$. This potential is the most used to describe of the evolution of water in liquid and saturated vapor forms.

One of the important thing for the molecular dynamic simulations to account for the effects of energy interchanging with the ambient is a special algorithm which is called a thermostat. In our work, we use Berendsen thermostat [Berendsen et al., 1984] to account for the effects of heat transfer between a vapor in the pore and the external environment. Coefficient of the velocity recalculation $\lambda(t)$ at every time step $t$ depends on the so called 'rise time' of the thermostat $\tau_{B}$ which belongs to the interval $[0.5,2] \mathrm{ps}$. This thermostat uses alternating nonlinear friction in equations of motion.

Equations of motion were integrated by Velocity Verlet method [Verlet, 1967].

In this paper it is used a flat pore model with dimensions of $1 \mu \mathrm{m} \times 1 \mu \mathrm{m} \times d$, where $d$ is the thickness of one layer of water molecules equal to the diameter of the molecule. Since it is assumed that the motion of molecules along the $z$ axis does not occur, this model is actually two-dimensional. The concentration of molecules, thus, is calculated as three-dimensional one, considering that water molecules are located in the volume $V=1 \mu \mathrm{m} \times 1 \mu \mathrm{m} \times d$. Initial concentrations were obtained from the density of water vapor at the appropriate pressure and density at a given temperature using known tabulated data. The pressure in the pore was controlled using the formula based on virial equation [Frenkel, Smith, 2002].

$$
P=\frac{1}{3 V}\left(\langle 2 K\rangle-\left\langle\sum_{i<j} r_{i j} \cdot f\left(r_{i j}\right)\right\rangle\right) .
$$


Here $V$ is the pore volume, $\langle 2 K\rangle$ is the doubled kinetic energy averaged over the ensemble, $f\left(r_{i j}\right)$ is the force between particles $i$ and $j$ at a distance $r_{i j}$.

\section{Macroscopic diffusion model}

Let us denote the water vapor concentration as $w_{v}(x, y, t)\left[\mathrm{ng} /(\mathrm{nm})^{2}\right]$ in the point $(x, y, t)$ where $x, y$ are space independent variables and $t$ is time independent variable. Then, we consider the following macroscopic diffusion model

$$
\begin{aligned}
& \frac{\partial w_{v}}{\partial t}=D\left(\frac{\partial^{2} w_{v}}{\partial x^{2}}+\frac{\partial^{2} w_{v}}{\partial y^{2}}\right), \quad 0<x<l_{x}, \quad 0<x<l_{y}, \quad t>0, \\
& w_{v}(x, y, 0)=w_{v, 0}, \quad 0 \leq x \leq l_{x}, \quad 0 \leq x \leq l_{y}, \\
& \left.\frac{\partial w_{v}}{\partial n}(t)\right|_{(x, y) \in \Gamma_{2} \cup \Gamma_{3} \cup \Gamma_{4}}=0, \quad t>0, \\
& -\left.D \frac{\partial w_{v}}{\partial x}(t)\right|_{\left(l_{x}, y\right) \in \Gamma_{1}}=\beta\left[w_{v}\left(l_{x}, y, t\right)-w_{v, \text { out }}(t)\right], \quad 0 \leq x \leq l_{y}, \quad t>0,
\end{aligned}
$$

where $D$ is the diffusion coefficient $\left[(\mathrm{nm})^{2} / p s\right] ; l_{x}, l_{y}$ are $2 \mathrm{D}$ pore dimensions $[\mathrm{nm}] ; w_{v, 0}$ is the initial concentration of water vapor; $\Gamma_{1}, \Gamma_{2}, \Gamma_{3}, \Gamma_{4}$ are boundaries of $2 \mathrm{D}$ pore; $\beta$ is the coefficient of water vapor transfer from pore space to outer space $[\mathrm{nm} / \mathrm{ps}] ; w_{v, \text { out }}(t)$ is the water vapor concentration in outer space $\left[\mathrm{ng} /(\mathrm{nm})^{2}\right]$.

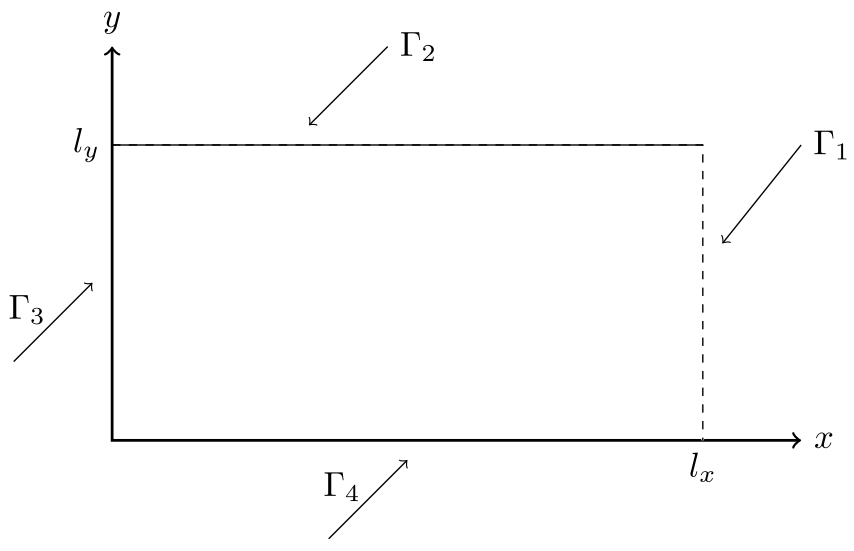

Fig. 2. Shape of 2D pore

We suppose that the outer space water vapor concentration is expressed as

$$
w_{v, \text { out }}(t)=\varphi_{0} \cdot w_{s v}\left(T_{0}\right),
$$

where $\varphi_{0}$ is the relative humidity of outer space $\left(0 \leq \varphi_{0} \leq 1\right)$ and $w_{s v}\left(T_{0}\right)$ is saturated water vapor concentration at outer temperature $T_{0}$.

The linear problem (1)-(4) can be solved exactly by means of the variables separation method [Bitsadze, Kalinichenko, 1980] and the result of the solution is the following

$$
\begin{gathered}
w_{v}(x, y, t)=w_{s v}\left(T_{0}\right) \cdot \varphi_{0}+\left[w_{v, 0}-w_{s v}\left(T_{0}\right) \cdot \varphi_{0}\right] \cdot \sum_{m=1}^{\infty} \sum_{n=0}^{\infty} e^{D \lambda_{m n} t} c_{m n} \cos \left(\alpha_{x m} x\right) \cos \left(\alpha_{y n} y\right), \\
0 \leq x \leq l_{x}, \quad 0 \leq y \leq l_{y}, \quad t \geq 0 .
\end{gathered}
$$


Here, $c_{m n}$ are coefficients of unity expansion

$$
c_{m n}= \begin{cases}\frac{4 \sin \left(\alpha_{x m} l_{x}\right)}{2 l_{x} \alpha_{x m}+\sin \left(2 \alpha_{x m} l_{x}\right)}, & \text { if } n=0, m=1,2,3, \ldots, \\ 0, & \text { if } n=1,2,3, \ldots, \quad m=1,2,3, \ldots,\end{cases}
$$

and $\lambda_{m n}$ are eigenvalues where

$$
\lambda_{m n}=-\alpha_{x m}^{2}-\alpha_{y n}^{2}, \quad \alpha_{y n}=\frac{n \pi}{l_{y}}, \quad n=0,1,2, \ldots,
$$

and $\alpha_{x m}$ are solutions of the equations

$$
\alpha_{x m} \cdot \tan \left(\alpha_{x m} l_{x}\right)=\beta / D, \quad m=1,2,3, \ldots
$$

\section{Computer simulation of micromodel}

We consider 2D macropore in the micromodel with dimensions $l_{x}=1 \mu \mathrm{m}, l_{y}=1 \mu \mathrm{m}$. The outer space in this micromodel reflects as a space right to the pore, see Fig. 3 (dashed line) which size, one can change by means of the parameter $k$. All sides of the outer space satisfy to the periodic boundary conditions. The left pore side reflects the inner molecules due to the boundary condition (3) but also provides the periodic boundary conditions for a part of outer space.

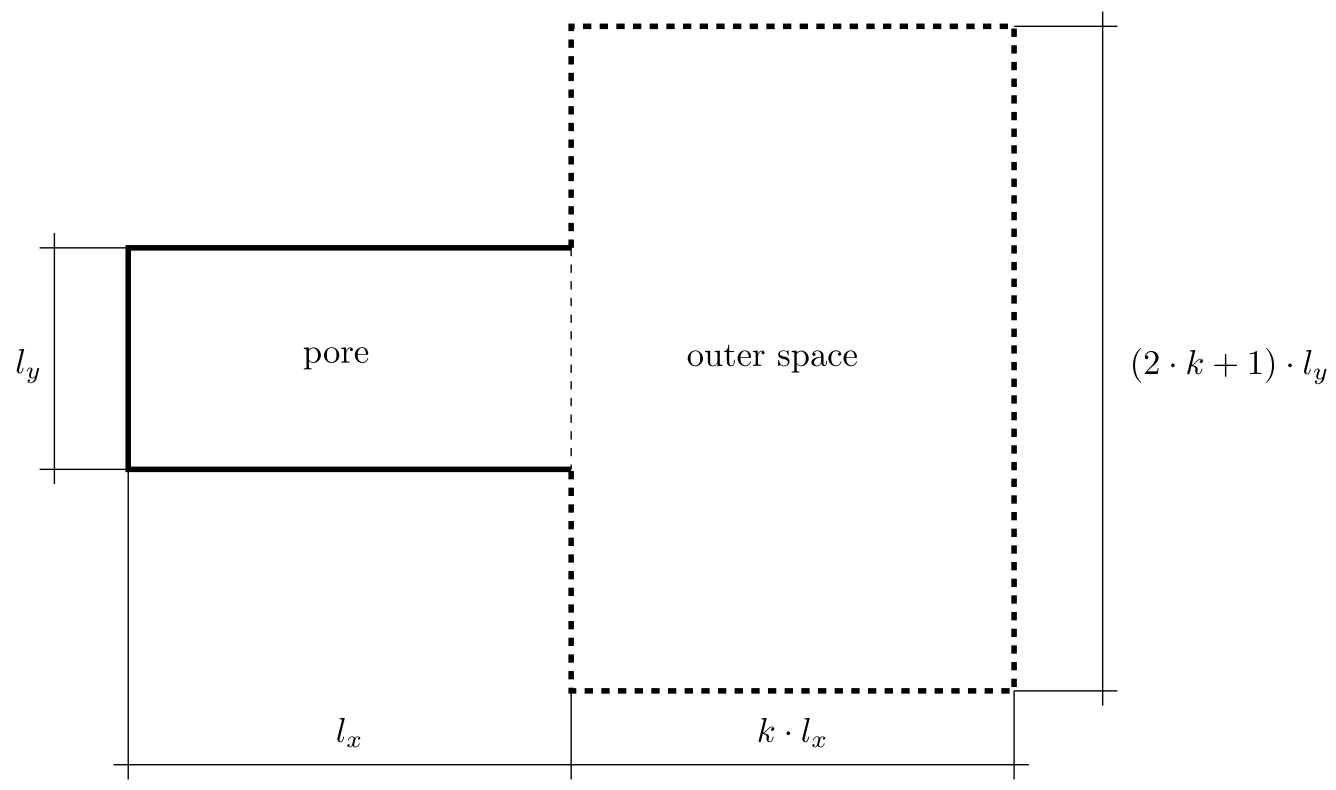

Fig. 3. 2D pore and outer space

The main characteristic of the diffusion process is the diffusion coefficient. In our micromodel we use the formula for diffusion coefficient calculations at each time step defined in the kinetic theory of gases

$$
D=\frac{1}{3}\langle v\rangle\langle\lambda\rangle,
$$

where $\langle v\rangle$ - the average velocity of molecules, $\langle\lambda\rangle-$ the mean free path of molecules.

One goal of the micromodel is to construct a constant diffusion coefficient which will then be used in the macromodel. In the figure 4 (left), we show the diffusion coefficients for both the pore $D_{p}(t)$ 
(upper predominantly decreasing curve) and the outer space $D_{\text {out }}(t)$ (lower predominantly increasing curve) for 244 starting $\mathrm{H}_{2} \mathrm{O}$ molecules in the pore. The middle curve is a mean of two previous diffusion coefficients and the constant diffusion coefficient value $D=1121.58\left[\mathrm{~m}^{2} / \mathrm{sec}\right]$ is represented in the figure 4 (left) as a horizontal line that was calculated according to the formula (6) [Krus, 1996].

$$
D=\frac{1}{t_{0}} \int_{0}^{t_{0}} \frac{D_{p}(t)+D_{\text {out }}(t)}{2} d t .
$$

The figure 4 (left) corresponds to a drying process of the pore when in the pore, we suppose 244 starting $\mathrm{H}_{2} \mathrm{O}$ molecules while in the outer space for $k=2$, we locate 490 starting $\mathrm{H}_{2} \mathrm{O}$ molecules. This means that the pore contains saturated water vapor at temperature $T_{0}=25{ }^{\circ} \mathrm{C}$ and at pressure $p_{0}=3.17 \mathrm{kPa}$ and the outer space contains only $20 \%$ of it. Thus, the outer space has $20 \%$ relative humidity.

The figure 4 (right) corresponds to a wetting process of the pore when in the pore, we locate 49 starting $\mathrm{H}_{2} \mathrm{O}$ molecules while in the outer space for $k=2$, we locate 2440 starting $\mathrm{H}_{2} \mathrm{O}$ molecules. This means that the outer space contains saturated water vapor at temperature $T_{0}=25{ }^{\circ} \mathrm{C}$ and at pressure $p_{0}=3.17 \mathrm{kPa}$ and the pore contains only $20 \%$ of it. Here, the upper curve represents the pore diffusion coefficient, the down curve represents the diffusion coefficient for outer space, the middle curve, as before, is a mean of two previous diffusion coefficients and the constant diffusion coefficient value $D=326.88\left[\mathrm{~m}^{2} / \mathrm{sec}\right]$ calculated according the formula (6) is represented in the Fig. 4 (right) as a horizontal line.

The Figure 5 refers to the case when the outer space is expanding $k=1,2,3$. The Figure 5 (left) concerns to the drying process while the Fig. 5 (right) concerns to the wetting process and both correspond to the same temperature, pressure and number of molecules like Fig. 4. In the Fig. 5 (left), upper curves starting near the point $(t, D)=(0,1900)$ correspond to the diffusion coefficients for the pore while the lower curves starting near the point $(t, D)=(0,400)$ correspond to the diffusion coefficients for the outer spaces. Similarly, in the Fig. 5 (right), upper curves starting near the point $(t, D)=(0,400)$ correspond to the diffusion coefficients for the pore while the lower curves starting near the point $(t, D)=(0,1900)$ correspond to the diffusion coefficients for the outer spaces.

A visualization of one possible case of molecular dynamic evolution of water vapor molecules distribution in a pore and an outer space for three time steps are shown in the Fig. 6.
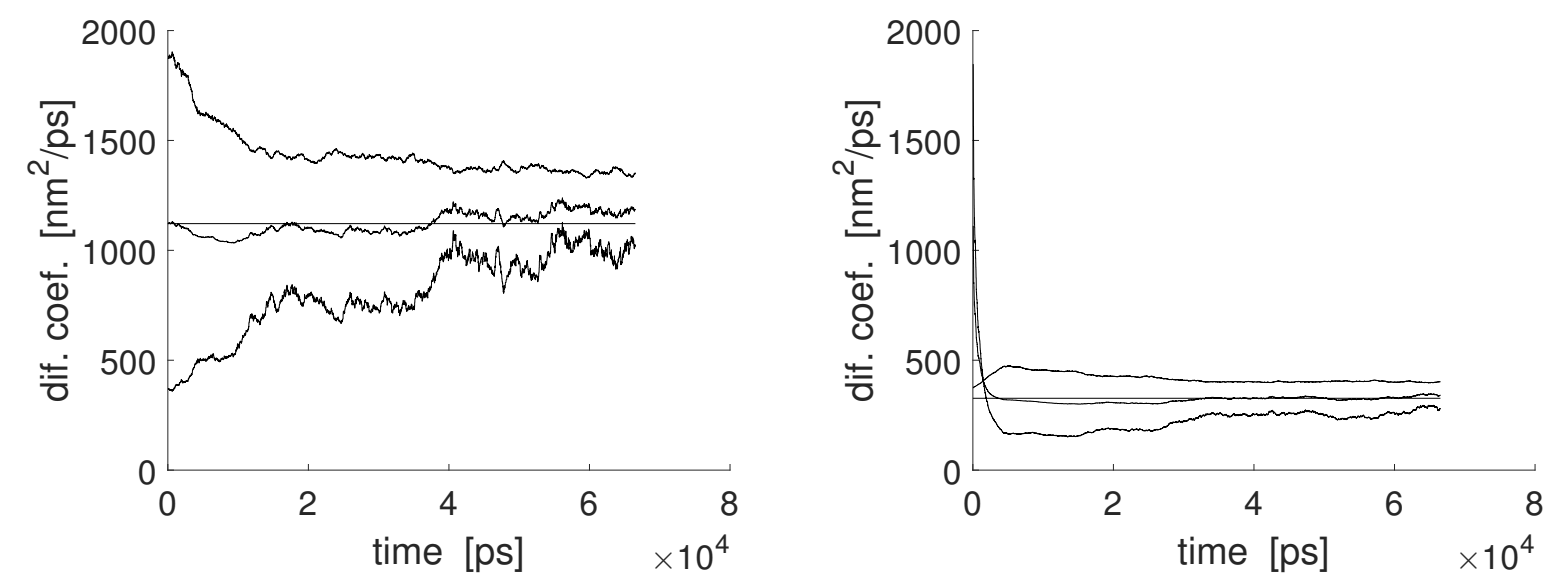

Fig. 4. Diffusion coefficients for drying process of the pore (left) and for wetting process of the pore (right), final time $t_{0}=66532 \mathrm{psec}$ 

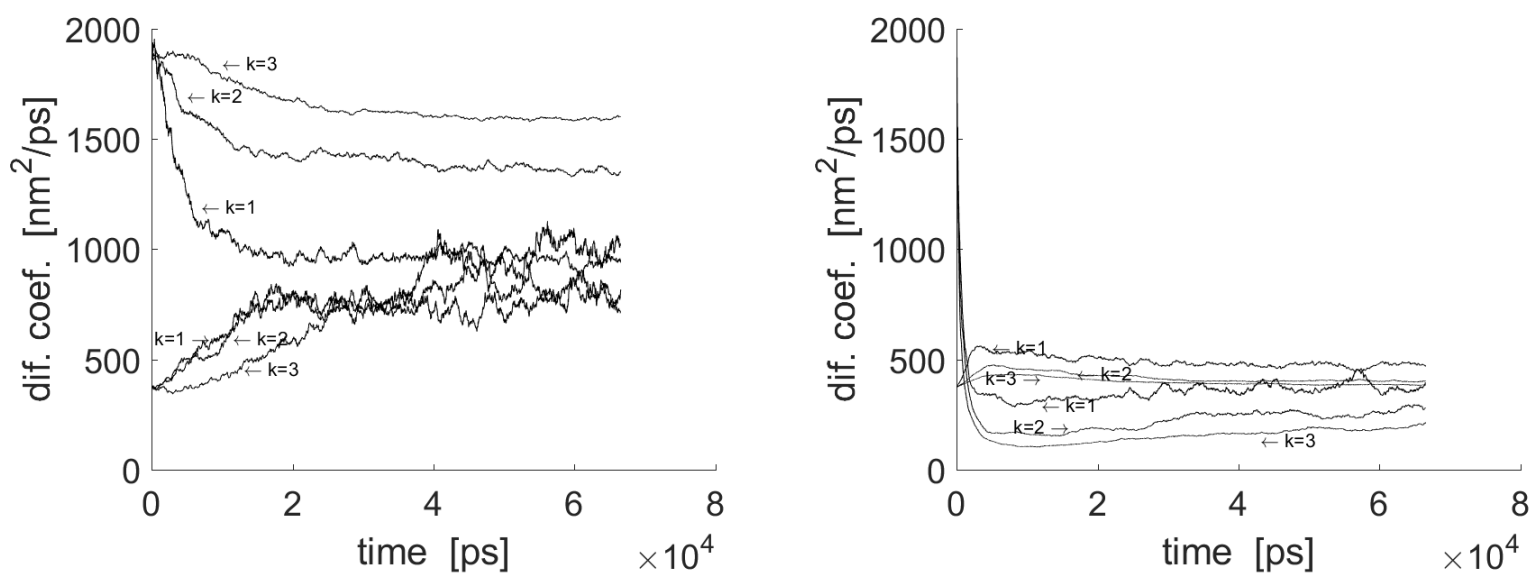

Fig. 5. Diffusion coefficients for drying process of the pore (left) and for wetting process of the pore (right) for expanded outer spaces $k=1,2,3$ and final time $t_{0}=66532 \mathrm{psec}$
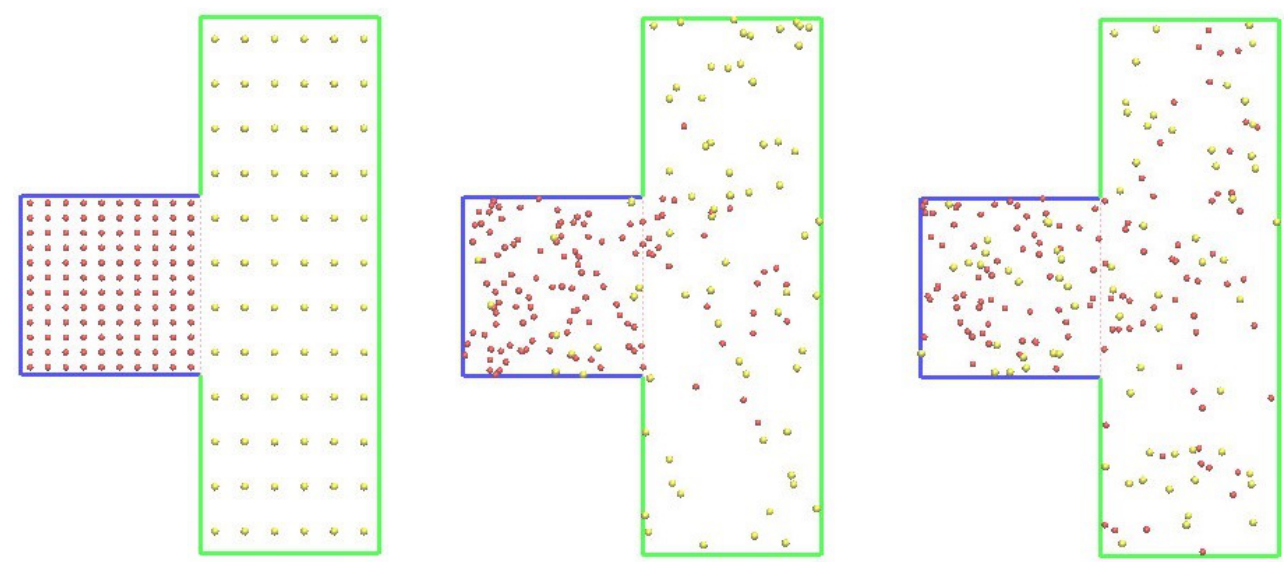

Fig. 6. Water vapor molecules distributions in pore and outer space at the beginning (left) and at two time moments

\section{Computer simulation of macromodel}

In previous part, we showed the results of the micromodel for the case of the saturated water vapor at temperature $T_{0}=25{ }^{\circ} \mathrm{C}$ and at pressure $p_{0}=3.17 \mathrm{kPa}$ and the outer space $k=2$ (see Fig. 3). Beside this case, we calculated also two other cases when the saturated water vapor at temperature $T_{0}=15{ }^{\circ} \mathrm{C}$ and at pressure $p_{0}=1.7 \mathrm{kPa}$, and the saturated water vapor at temperature $T_{0}=35{ }^{\circ} \mathrm{C}$ and at pressure $p_{0}=5.62 \mathrm{kPa}$ and for different outer spaces $k=1,2,3$. Each of these cases provides a constant diffusion coefficient calculated according the formula (6) for different outer spaces $k=1,2,3$. The corresponding constant diffusion coefficient values are summarized in the Table 1 .

The micromodel provides also another important characteristic like the density of $\mathrm{H}_{2} \mathrm{O}$ molecules in the pore. The density can be compared by a space mean of water vapor concentration which can be calculated from the solution (5) according the following formula (7):

$$
w_{s m}(t)=\frac{1}{l_{x} l_{y}} \int_{0}^{l_{x}} \int_{0}^{l_{y}} w_{v}(x, y, t) d x d y .
$$


Table 1. Constant diffusion coefficients for different temperatures calculated according to the formula (6); previously commented constants are in bold

\begin{tabular}{|r||r|r|r||r|r|r|}
\hline \multicolumn{1}{|c||}{$T\left[{ }^{\circ} \mathrm{C}\right]$} & \multicolumn{3}{c||}{ Drying } & \multicolumn{3}{c|}{ Wetting } \\
\cline { 2 - 7 } & $k=1$ & $k=2$ & $k=3$ & $k=1$ & $k=2$ & $k=3$ \\
\hline \hline 15 & 1542.39 & 1994.85 & 2091.06 & 760.64 & 579.73 & 501.83 \\
\hline 25 & 867.11 & $\mathbf{1 1 2 1 . 5 8}$ & 1169.05 & 427.82 & $\mathbf{3 2 6 . 8 8}$ & 282.44 \\
\hline 35 & 511.37 & 655.71 & 674.51 & 255.74 & 193.44 & 168.95 \\
\hline
\end{tabular}
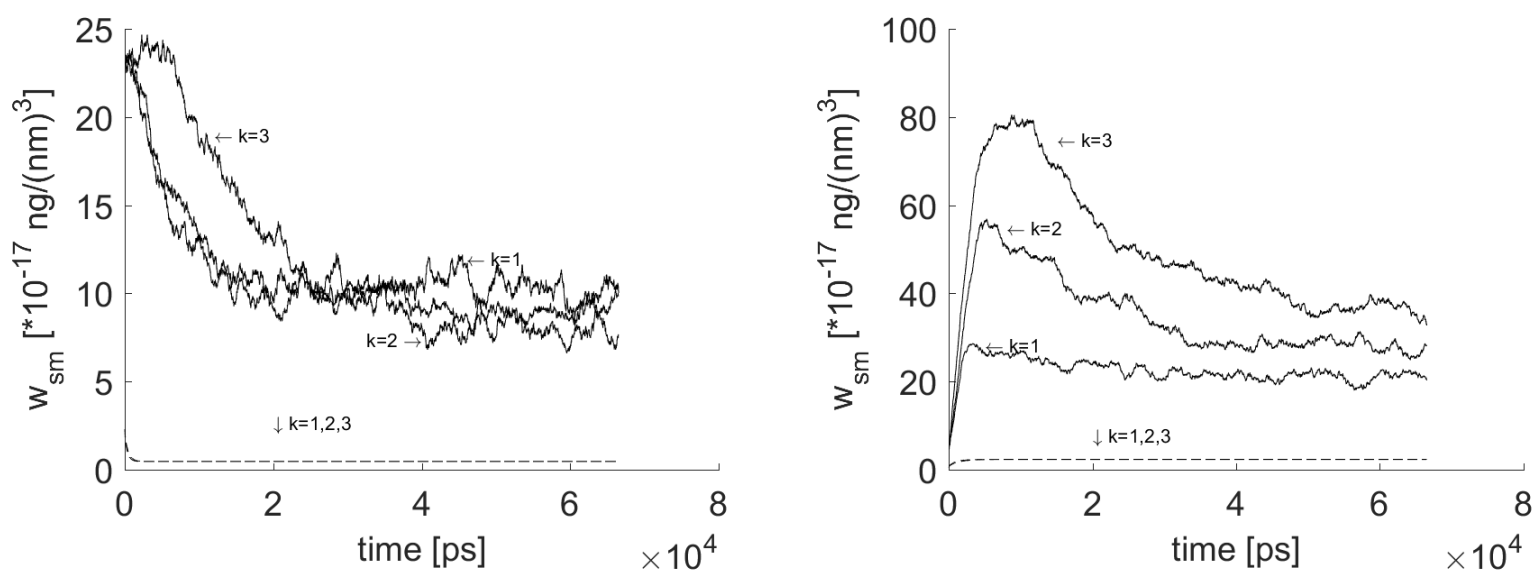

Fig. 7. Dynamics of the space mean of water vapor concentration (dashed curves) and dynamics of density (bulk curves) for final time $t_{0}=66532 \mathrm{psec}$. Drying process (left) and wetting process (right)

Dynamics of the space mean of water vapor concentration $w_{s m}(t)$ and dynamics of density for final time $t_{0}=66532 \mathrm{psec}$ and for the saturated water vapor at temperature $T_{0}=25{ }^{\circ} \mathrm{C}$ and at pressure $p_{0}=3.17 \mathrm{kPa}$ and the outer space $k=1,2,3$ are shown in figure 7 .

\section{Conclusions}

The both models give a consistent description of water vapor and a pore interaction in 2D case. The both models are consistent with experiment results concerning diffusion coefficient values. It is possible to use so called "hybrid" (a combination of micro and macro) approach for more accurate simulation of "water vapor-pore" interaction processes. But one can see from results of molecular dynamic simulations that the macro and the micro approaches are closer if a number of molecules used in molecular dynamic calculations is sufficient for selected ambient temperature and pressure which agrees well with the conclusions of the article [Norman, Stegailov, 2012]. It means that these calculations are also more realistic.

\section{References}

Berendsen H.J.C., Postma J.P.M., van Gunsteren W. F., DiNola A., Haak J. R. Molecular dynamics with coupling to an external bath // J. Chem. Phys. - 1984. - Vol. 81. - P. 3684-3690.

Bitsadze A. V., Kalinichenko D.F. A Collection of Problems on The Equations of Mathematical Physics. - Mir Publishers, 1980.

ČSN 730542 Tepelně technické vlastnosti stavebních konstrukcí a budov, Vydavatelství úřadu pro normalizaci a měření. - Praha, schválená 4.3.1977, účinnost od 1.1.1979. - P. 67. 
Gould H., Tobochnik J., Christian W. An Introduction to Computer Simulation Methods. - Chapter 8. Third edition. - 2005. - P. 267-268.

Frenkel D., Smith B. Understanding molecular simulation: from algorithms to applications. - Second edition. - Academic Press, 2006. - 658 p.

Hairer E., Lubich C., Wanner G. Geometric Numerical Integration. - Second edition. - Springer, 2006.

Krus M. Moisture transport and storage coefficients of porous minearal building materials: Theoretical principals and new test method. - Stuttgart: Fraunhofer IRB Verlag, 1996. - P. 18.

Lennard-Jones J.E. On the Determination of Molecular Fields // Proc. Roy. Soc. - 1924. Vol. A 106. - P. 463-477.

Marchuk G. I. Handbook of numerical analysis, Vol. 1: Splitting and alternating direction methods. North Holland, Amsterdam, 1990. - P. 197-462.

McNaught A.D., Wilkinson A. IUPAC. Compendium of Chemical Terminology, 2nd ed. (the "Gold Book"). - Blackwell Scientific Publications, Oxford, 1997.

Norman G.E., Stegailov V.V. Stochastic theory of the classical molecular dynamics method // Math. Models Comput. Simul. - 2013. - Vol. 5, No. 4. - P. 305-333. Doi: $10.1134 / \mathrm{S} 2070048213040108$

Rouquerol J., Avnir D., Fairbridge C. W., Everett D. H., Haynes J. H., Pernicone N., Ramsay J. D. F., Sing K.S. W., Unger K. K. Recommendations for the Characterization of Porous Solids (Technical Report) // Pure and Appl. Chem. - 1994. - Vol. 66. - P. 1739-1758.

Samarskii A.A., Vabishchevich P.N. Additive schemes for problems of mathematical physics. Moscow: Nauka, 1999.

International Bureau of Weights and Measures, International System of Units (SI). - Eight edition, 2006. - P. 114-115.

Shaytan K.B., Saraykin S.S. Molecular dynamics. - 1999. - Web Access: http://www.library.biophys.msu.ru/MolDyn/

Verlet L. Computer "experiments" on classical fluids. I. Thermodynamical properties of Lennard-Jones molecules // Phys. Rev. - 1967. - Vol. 159. - P. 98-103. 